\title{
Determination of Lead and Cadmium in Synthetic and Natural Hair Dyes in Morocco Using Differential Pulse Polarography
}

\author{
M. Benabbes ${ }^{a}{ }^{*}$, M. Alami Chentoufi ${ }^{a}$, B. Mojemmi ${ }^{a}$, H. Benzeid ${ }^{a}$, \\ H. A Touré ${ }^{a}$, A. Cheikh ${ }^{b}$, Y. Rahalic, M. O.B. Idrissi ${ }^{a}$, \\ M. Draoui ${ }^{a}$ and M. Bouatia ${ }^{a}$ \\ ${ }^{a}$ Laboratory of Analytical Chemistry, Faculty of Medicine and Pharmacy, \\ Mohammed V University, Rabat, Morocco \\ ${ }^{b}$ Faculty of Pharmacy, Abulcasis University, Rabat, Morocco \\ ${ }^{c}$ Team of Formulation and Quality Control of Health Products, \\ Faculty of Medicine and Pharmacy, Mohammed V University-Rabat, Morocco
}

Received June 5, 2018; accepted August 5, 2020

\begin{abstract}
The concentrations of lead and cadmium were determined in markets of hair dyes samples in Morocco. Sixteen synthetic and natural hair dyes were selected. The metals were analyzed after mineralization with nitric acid and hydrogen peroxide. The content was determined using differential pulse polarography and the analytical method was validated. The method was linear with a correlation coefficient value (r) that ranged from 0.992 to 0.999 . The limit of detection (LOD) was 0.080 and $0.43 \mathrm{ppm}$ for $\mathrm{Pb}$ and $\mathrm{Cd}$, respectively. Finally, the concentrations of the two metals in the different hair dyes samples ranged from LOD to $3617.02 \mathrm{ppm}$ for $\mathrm{Pb}$ and from LOD to $459.57 \mathrm{ppm}$ for $\mathrm{Cd}$. The majority of the concentrations were above acceptable levels for cosmetics. It has been demonstrated that heavy metals induce toxicity to human body even at a low level, hence the need to strengthen the control of cosmetic products by the competent authorities in Morocco.
\end{abstract}

Keywords: Lead, cadmium, heavy metals, cosmetic and polarography.

\section{Introduction}

A cosmetic product, as defined by the 1223/2009 European Cosmetic Regulation, is any substance or mixture intended to be placed in contact with the external parts of the human body (epidermis, hair system, nails, lips and external genital organs) or with the teeth and the mucous membranes of the oral cavity, with an exclusive or main view to clean them, perfume them, change their appearance, protect them, keep them in good condition or correct body odors. Hair dyes or

\footnotetext{
*Corresponding author. E-mail address: benabbesmajda@gmail.com
} 
hair coloring products present one of the cosmetics products most used by the Moroccan population. Their use, both by men and women, continues to grow following fashion trends. Heavy metals are identified as one of the important contaminants in cosmetics products. Lead (as acetate) is used as a color additive in hair dyes $(1,2)$.

Some studies have demonstrated that the skin exposure to low levels of lead in hair dyes and tattoos may cause many health effects such as behavioral abnormalities, learning impairment, decreased hearing and impaired cognitive function. Cadmium is used in cosmetic products for its color property and it is added as impurities during the manufacturing process. Many studies described cadmium as carcinogenic and as a substance that may cause kidney damage for patients chronically exposed to it.

Other studies showed a relation between the exposure to cadmium and bone damage, with apparition of some symptoms such as low grade of bone mineralization, high rate of fractures and increased rate of osteoporosis $(3,4)$.

The toxicology and risk assessment of hair dyes have been subjects of many studies. These products are identified as the origin of various types of health problems, notably contact allergy, carcinogenicity, genetic and reproductive toxicity (5-7).

The present study aims to determine the concentration of lead and cadmium in different brands of hair dyes samples collected from the Moroccan market.

Among many methods described in the literature for trace determination, we chose differential pulse polarography (DPP), which is a very sensitive electrochemical method for the determination of heavy metals in aqueous media (8).

\section{Materials and methods \\ Instrumentation}

All experiments were performed using a 797 VA Computrace (Metrohm, Germany) for polarographic trace analysis.

The differential pulse polarography technique (DPP) was used for the quantitative determination. The cell was equipped with three electrodes: the working electrode was a dropping mercury electrode (DME), platinum was used as counter electrode and $\mathrm{Ag} / \mathrm{AgCl} /(3 \mathrm{M} \mathrm{KCl})$ as reference electrode. Nitrogen was used as an inert gas to operate the mercury electrode and to purge the analyte solutions.

The electrode drop time was $0.4 \mathrm{~s}$. The polarograms were obtained by scanning the potential from $-0.2 \mathrm{~V}$ to $-0.7 \mathrm{~V}$, with a pulse amplitude of $50 \mathrm{mV}$. The mineralization was performed using the Multiwave PRO microwave system (Anton Paar).

\section{Reagents and solutions}

Pure mercury (99.9\%), hydrogen peroxide (30\%), potassium chloride, trace metal free nitric acid (65\%, suprapure), lead nitrate and cadmium chloride were of analytical grade. 
A standard solution of $1000 \mathrm{mg} . \mathrm{L}^{-1}$ of lead $(\mathrm{Pb})$ was prepared using nitrate salts $\left(\mathrm{Pb}\left(\mathrm{NO}_{3}\right)_{2}\right.$, and the standard solution of $1000 \mathrm{mg} . \mathrm{L}^{-1}$ of cadmium $(\mathrm{Cd})$ was prepared using cadmium chloride $\left(\mathrm{CdCl}_{2}\right)$. All solutions were prepared in double distilled water.

\section{Sample mineralization and electrochemical analysis}

Synthetic hair dyes and natural hair dyes samples were bought from Moroccan markets. Sixteen hair dyes were chosen. The brands, colors and their origin are listed in Table 1.

Table 1. List of tested brands, colors, and their country of origin.

\begin{tabular}{|c|c|c|}
\hline Brand & Color & Country of origin \\
\hline Brand-1-a & Very light blonde & French \\
\hline Brand-1-b & Light ash blonde & French \\
\hline Brand-1-c & Brown & French \\
\hline Brand-1-d & Dark ash blonde & French \\
\hline Brand-2-a & Light brown & USA \\
\hline Brand-2-b & Dark blonde & USA \\
\hline Brand-3-a & Medium intense violet & Italy \\
\hline Brand-3-b & Light warm blonde & Italy \\
\hline Brand-3-c & Very light blonde & Italy \\
\hline Brand-4-a & Brown & Emirates (UAE) \\
\hline Brand-4-b & Maroon & Emirates (UAE) \\
\hline Brand-4-c & Dark brown & Emirates (UAE) \\
\hline Brand-5-a & Medium brown & Germany \\
\hline Brand-5-b & Light brown & Germany \\
\hline Brand-5-c & Medium natural brown & USA \\
\hline Brand 6 & Dark brown & French \\
\hline
\end{tabular}

SHD: Synthetic Hair dye; NHD: Natural Hair dye.

\section{Mineralization}

A sample of $200 \mathrm{mg}$ was placed in Teflon vessels and reacted with $4 \mathrm{~mL}$ of $\mathrm{HNO}_{3}$ for 4 hours in room temperature. After adding $1 \mathrm{~mL}$ of hydrogen peroxide, the sample solutions were putted into the microwave oven at $230{ }^{\circ} \mathrm{C}$ for $15 \mathrm{~min}$. A blank solution was treated with the same protocol. The extracts were transferred to a polypropylene tube closed with a sealed cap.

\section{Electrochemical analysis}

Twenty milliliters of distilled water, $1 \mathrm{~mL}$ of supporting electrolyte and a sample of $100 \mu \mathrm{l}$ were introduced into a polarographic cell. The supporting electrolyte 
was $1 \mathrm{M}$ of KCL for both heavy metals. In the process of measurement, the solution was bubbled with pure nitrogen $(99.999 \%)$ for $180 \mathrm{~s}$ and after each analysis. The standard addition technique was used for the determination of heavy metals by three times additions of $100 \mu \mathrm{L}$ of the standard solution in each addition.

\section{Method validation}

The method was validated according to ICH guidelines (9). The lead and cadmium curves calibrations were prepared each day during three days using the standard addition method. A known quantity of lead and cadmium standard solutions were added to give final concentrations in the range from 10 to $60 \mathrm{ppm}$ for lead and in the range from 40 to $640 \mathrm{ppm}$ for cadmium. The validation was carried out by studying the following parameters: linearity, accuracy, limit of detection (LOD), limit of quantitation (LOQ) and precision. The precision of the method was express as repeatability. LOQ and LOD were determined according to $\mathrm{ICH}$ recommendations: $\mathrm{LOD}=3(\sigma / \mathrm{S})$ and $\mathrm{LOQ}=10(\sigma / \mathrm{S})$, where $\sigma$ is the standard deviation and $\mathrm{S}$ is the slope of the linear dynamic range.

\section{Results}

\section{Method validation}

The method has shown good linearity for both metals, with correlation coefficient values (r) of 0.992 and 0.999 for $\mathrm{Cd}$ and $\mathrm{Pb}$, respectively. A good linear relationship was obtained; concentration was in the range from LOQ-0.6 $\mathrm{mg} \mathrm{L}^{-1}$ to LOQ- $0.64 \mathrm{mg} \mathrm{L}^{-1}$ for $\mathrm{Pb}$ and $\mathrm{Cd}$, respectively. Due to the unavailability of an analyte free matrix, the accuracy was determined using a standard addition analysis technique. The analysis was conducted on the finished product spiked with a known amount of each metal. The results of the analytical validation method are given in Table 2.

Table 2. Results of analytical validation method.

\begin{tabular}{cccccc}
\hline Analyte & $\begin{array}{c}\text { Linearity } \\
\text { (r) }\end{array}$ & $\begin{array}{c}\text { Accuracy } \\
\text { (recovery } \pm \text { RSD) }\end{array}$ & $\begin{array}{c}\text { Precision } \\
(\mathbf{C V} \%)\end{array}$ & $\begin{array}{c}\text { LOD } \\
\text { (ppm) }\end{array}$ & $\begin{array}{c}\text { LOQ } \\
\text { (ppm) }\end{array}$ \\
\hline $\mathbf{P b}$ & 0.992 & $100.33 \pm 4.9 \%$ & 0.72 & 0.080 & 0.243 \\
$\mathbf{C d}$ & 0.999 & $102.60 \pm 0.87 \%$ & 0.93 & 0.43 & 1.31 \\
\hline
\end{tabular}

\section{Determination of lead and cadmium in hair dyes}

Sixteen hair dyes were selected for the separate analysis of $\mathrm{Pb}$ and $\mathrm{Cd}$ using differential pulse polarography. The data presented in Table 3 show a summary of the descriptive statistical analysis of heavy metals in hair dyes.

\section{Lead content in hair dyes}

The overall median concentration $(\mathrm{n}=16)$ of $\mathrm{Pb}$ analyzed was $1196.17 \mathrm{ppm}$ $[\mathrm{Q} 1=960.69$; $\mathrm{Q} 3=1490.19]$. The highest concentration of $\mathrm{Pb}$ was obtained in brand-4-c (3617.02 ppm) and a non-detectable concentration was obtained in both hair dyes of brand 2 and brand-5-c. In the sixteen samples of brands of hair 
dyes, thirteen samples with extremely high lead level ranged from 448.43 to $3617.02 \mathrm{ppm}$. The $\mathrm{Pb}$ concentration in brown dyes of brands-1-3-4-5 was higher than that of other brown shades of the rest of brands and the $\mathrm{Pb}$ level in blonde dyes of brands-1-3 was considerately higher than that of other blonde shades. The brand-2 was the only brand where $\mathrm{Pb}$ has not been detected.

Table 3. Descriptive statistical summary of heavy metal concentration (mean $\pm \mathrm{SD}$ ) for six different brands in ppm and their price.

\begin{tabular}{lllll}
\hline Brand & Color & $\begin{array}{l}\text { Pb } \\
(\mathbf{p p m})\end{array}$ & $\begin{array}{l}\text { Cd } \\
\mathbf{( p p m )}\end{array}$ & $\begin{array}{l}\text { Price } \\
(\mathbf{\epsilon})\end{array}$ \\
\hline Brand-1-a & Very light blonde & $1324,20 \pm 0.001$ & $54.79 \pm 0.0001$ & 11.50 \\
Brand-1-b & Light ash blonde & $1042.65 \pm 0.001$ & $56.87 \pm 0.0001$ & 11.50 \\
Brand-1-c & Brown & $1106.19 \pm 0.001$ & $53.09 \pm 0.0001$ & 11.50 \\
Brand-1-d & Dark ash blonde & $960.69 \pm 0.001$ & $52.40 \pm 0.0001$ & 11.50 \\
Brand-2-a & Light brown & $<$ LOD & $113.20 \pm 0.0001$ & 8.30 \\
Brand-2-b & Dark blonde & $<$ LOD & $105.26 \pm 0.0001$ & 10. \\
Brand-3-a & Medium intense violet brown & $1490.19 \pm 0.001$ & $<$ LOD & 12.16 \\
Brand-3-b & Light warm blonde & $448.43 \pm 0.001$ & $53.81 \pm 0.0001$ & 12.16 \\
Brand-3-c & Very light blonde & $1574.07 \pm 0.001$ & $55.55 \pm 0.0001$ & 12.16 \\
Brand-4-a & Brown & $676.32 \pm 0.001$ & $<$ LOD & 2 \\
Brand-4-b & Maroon & $1743.55 \pm 0.001$ & $<$ LOD & 2 \\
Brand-4-c & Dark brown & $3617.02 \pm 0.001$ & $459.57 \pm 0.0001$ & 2 \\
Brand-5-a & Medium brown & $1196.17 \pm 0.001$ & $57.41 \pm 0.0001$ & 6.79 \\
Brand-5-b & Light brown & $1414.63 \pm 0.001$ & $<$ LOD & 7.95 \\
Brand-5-c & Medium brown naturel & $<$ LOD & $<$ LOD & 9.24 \\
Brand 6 & Brown & $585.93 \pm 0.001$ & $46.87 \pm 0.0001$ & 6.89 \\
\hline
\end{tabular}

\section{Cadmium content in hair dyes}

The overall $(\mathrm{n}=16)$ average concentration of $\mathrm{Cd}$ analyzed was $55.55 \mathrm{ppm}$ $[\mathrm{Q} 1=53.54 ; \mathrm{Q} 3=81.33]$, with the highest concentration in brand-4-c $(459.57 \mathrm{ppm})$, and a non-detectable concentration in brand-3-a, brand-4-a, brand$4-b$, brand-5-b and brand-5-c.

$\mathrm{Cd}$ concentrations in all samples of brand-1 were very similar, and the same goes for brand-2 and brand-3, except brand-3-a. The Cd concentration of dark brown dye of a natural hair dye (brand-4-c) was the highest concentration.

In the total, $\mathrm{Pb}$ and $\mathrm{Cd}$ have not been detected in medium brown natural shade from brand-5-c. On the other side, when comparing the results, the concentration of heavy metals is not related to brands in our study.

In conclusion, ten products have rates outside the acceptance limit for $\mathrm{Pb}$ and nine for $\mathrm{Cd}$. The correlation test (Pearson) between concentration of heavy metals in hair dyes and the price was carried out. The two parameters were negatively correlated: $\mathrm{r}=-0,399$ for $\mathrm{Pb}$ and $\mathrm{r}=-0,354$ for $\mathrm{Cd}$; this outcome means that the concentration of heavy metals increases with the decrease in price. 


\section{Discussion}

The heavy metals content in cosmetic products is not regulated by the Moroccan authorities, and the values for the impurities of these substances are not standardized. However, it is admitted that lead and cadmium impurities in cosmetic products are unavoidable, due to the ubiquitous nature of these elements. The Health department from Canada states that heavy metal impurity concentrations in cosmetic products are technically avoidable when they exceed the following limits: 10 ppm for lead and 3 ppm for cadmium (10).

The German federal government has defined a maximum level of heavy metals in toothpastes and other cosmetic products and the levels of lead and cadmium are considered technically avoidable above, respectively, 20 ppm and 5 ppm (11, 12). FDA has published a guidance that recommends a level of $10 \mathrm{ppm}$ for lead as an impurity in cosmetics. The same organization has conducted two surveys to determine cadmium and other-heavy metals in a wide variety of cosmetic products, but the acceptable level of lead and cadmium in hair dyes has not been set (13). On the other side, the United Kingdom reported that a concentration of $1 \%$ of lead is still admitted in hair dyes (14).

The hair dyes are classified into four categories: oxidative (permanent) dyes, direct (temporary or semi-permanent) dyes, metal salts and natural dyes (15).

In the present study, thirteen samples of direct dyes and three natural dyes were selected from different manufacturer's countries and analyzed thereafter. A very high level of lead was detected in tested hair dyes according to all the limits mentioned before, and only three shades have a lead concentration below the LOD. The highest concentration of lead was obtained in a natural dye (brand-4c); that result is in accordance with the result of Ozbek et al., which found a significantly higher lead level in natural hair dyes than that of the synthetics.

A second study of Jallad et al. reported the same outcome $(15,16)$. Henna-based natural dyes are not subject to the regulation of cosmetic products in Morocco, which may explain this high contamination by lead. The manner in which Moroccan women use the henna may develop the risk of intoxication. They apply the product for a long duration to obtain a good coloration, but this theory needs more investigations.

Another study about the determination of lead in hair dyes carried out on the Baghdad market in Iraq reported a maximum lead level of $0.92 \mathrm{ppm}$; that is much lower than the maximum reported in our study (1574.07 ppm) (17). This outcome may be attributed to the different origins of samples from various producers. Cadmium was not detected in five samples of hair dyes, while a cadmium concentration of 46.87 to $459.57 \mathrm{ppm}$ was detected in the other hair dyes, which are higher than the limit fixed by various regulations $(10,11)$. The highest level of cadmium was found in a natural dye (brand-4-c), which also has the highest concentration of lead.

The concentration of cadmium in our synthetic hair dyes samples was higher than those reported by a study carried out in Nigeria, and higher than cadmium concentrations of natural hair dyes in the Turkey market $(15,18)$. Cadmium was reported as one of the toxic heavy metals causing harmful effects in a wide range of organs, which has an elimination half-life of 10-30 years (19). Cadmium 
toxicity includes renal, bone, kidney, dermal and metabolic damage. The exposure to low levels has been associated with cancer and heart diseases (19, 20).

For both analyzed metals, our results allow us to conclude that there is no automatic link between the lead content and brand or shades. On the other hand, the correlation between the concentration of heavy metals and the price was negative for both metals. This result can be explained by the fact that the producers who fix a higher price invest more in the control of their products. This correlation may also be due to the difference in the technologies used by each producer. Of course, there are some exceptions to those conclusions.

\section{Conclusion}

In the current study, lead and cadmium were determined in various synthetic and natural hair dyes using differential pulse polarography. A high concentration of both metals was found on many hair dyes, but the highest concentration was detected in one sample of natural hair dyes.

The use of cosmetic products contaminated with such metals can cause serious problems to the human body. These results represent new data on heavy metals in a category of cosmetic products marketed in Morocco and highlight the need to regulate the sector in order to protect the consumers.

\section{Acknowledgement}

The authors would like to acknowledge the team of Laboratory of Analytical Chemistry, Faculty of Medicine and Pharmacy, Mohammed V University, for their collaboration.

\section{References}

1. Chauhan AS, Bhadauria R, Singh AK, et al. Determination of Lead and Cadmium in cosmetic products. J Chem Pharm Res. 2010;2:92.

2. Shih Y, Zen J-M, Kumar AS, Lee YC, et al. Determination of the Toxic Lead Level in Cosmetic-Hair Dye Formulations Using a Screen-Printed Silver Electrode. Bull Chem Soc Jap. 2004;77:311.

3. Iwegbue C, Onyeloni SO, Bassey FI, et al. Safety Evaluation of Metal Exposure From Commonly Used Hair Dyes and Tattoo Inks in Nigeria. J Environ Health. 2016;78:26.

4. Cha N-R, Lee J-K, Lee Y-R, et al. Determination of Iron, Copper, Zinc, Lead, Nickel and Cadmium in Cosmetic Matrices by Flame Atomic Absorption Spectroscopy. Anal Lett. 2010;43:259.

5. Uter W, Lessmann H, Geier J, et al. Contact allergy to hairdressing allergens in female hairdressers and clients - current data from the IVDK, 2003-2006. J Deut Dermatol Gesellschaft. 2007;5:993.

6. Sanjeev H, Rahul M, Dipankar D. Contact dermatitis to hair dye: an update. Indian J Derm, Vener Lep. 2012;78:583. 
7. Nohynek GJ, Antigna E, Re T, et al. Safety assessment of personal care products/cosmetics and their ingredients. Tox Appl Pharm. 2010;243:239.

8. Koçak S, Tokuşoğlu Ö, Aycan Ş. Some heavy metal and trace essential element detection in canned vegetable foodstuffs by differential pulse polarography. Elect J Environ, Agric Food Chem. 2005;4:871.

9. Shabir G. Validation of high-performance liquid chromatography methods for pharmaceutical analysis: Understanding the differences and similarities between validation requirements of the US Food and Drug Administration, the US Pharmacopeia and the International Conference on Harmonization Journal of Chromatography A. 2003;987:57.

10. Health Canada. Guidance on Heavy Metal Impurities in Cosmetics [Available from: https:/www.canada.ca/en/healthcanada/services/consumer-product-safety/reports-publications/industryprofessionals/guidance-heavy-metal-impurities-cosmetics.html [Accessed 25th May 2018].

11. Al-Dayel O, Hefne J, Al-Ajyan T. Human Exposure to Heavy Metals from Cosmetics. Orient J Chem. 2011;27:1.

12. Issa IYS, Abdel Maguid R. Determination of Toxic Contents and Metals in Different Cosmetic Products in the Arabian Market. J Environ Anal Toxic. 2016;6.

13. Food and Drug Administration. Draft Guidance for Industry: Lead in Cosmetic Lip Products and Externally Applied Cosmetics: Recommended Maximum Level [Available from: https://www.fda.gov/Cosmetics/GuidanceRegulation/GuidanceDocuments/ ucm452623.htm_[Accessed 25th May 2018].

14. Lansdown A. Lead in hair dye, short-term appeal vs. long-term risk. Int J Cosmetic Sci. 2000;22:167.

15. Ozbek N, Akman S. Determination of lead, cadmium and nickel in hennas and other hair dyes sold in Turkey. Reg Toxic Pharm. 2016;79:49.

16. Jallad KN, Espada-Jallad C. Lead exposure from the use of Lawsonia inermis (henna) in temporary paint-on-tattooing and hair dying. Sci Total Environ. 2008;397:244.

17. Hussein HJ. Evaluation of the Concentration of Some Heavy Metals in Hair Dyes in Baghdad. Int J Sci Res. 2015;4.

18. Sani A, Gaya MB, Abubakar FA. Determination of some heavy metals in selected cosmetic products sold in kano metropolis, Nigeria. Toxicology Rep. 2016;3:866.

19. Patrick L. Toxic Metals and Antioxidants: Part II. The Role of Antioxidants in Arsenic and Cadmium Toxicity. Alt Medic Rev. 2003;8.

20. Nourmoradi H, Foroghi M, Farhadkhani M, et al. Assessment of lead and cadmium levels in frequently used cosmetic products in Iran. J Environ Public Health. 2013;2013:962727. 